\title{
Upgrading Development and Application of Agricultural Information Service System Based on WeChat Public Platform- -A Case of WeChat Public Platform of 12396 Beijing new rural sci-tech service hotline
}

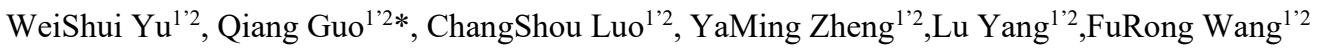 \\ ${ }^{1}$ Institute of Agricultural Information and Economics, Beijing Academy of Agriculture and Forestry Sciences, Beijing, 100097, China \\ ${ }^{2}$ Rural Distance Information Service Engineering Technology Research Center of Beijing, Beijing, 100097, China
}

\begin{abstract}
The WeChat public platform is a new service platform based on WeChat applications that provides business services and user management for individuals, businesses and organizations. It provides a new solution to the lag of agricultural information dissem-ination in the traditional media. However, services based on Tencent's backend can only meet the basic needs of users and reduce the user's experience in agricultural science and technology consulting process. In order to provide efficient and convenient service to users and solve existing problems in consultation process, the platform-related API were used to upgrade the 12396 hotline WeChat public platform to an integrated agricultural information interactive service system. It mainly carries out the following three aspects to upgrade development. Firstly, 12396 hotline WeChat public platform added two sub-menu items, "use ask" and "expert answer" to push the user's question to expert directly, reducing the backend customer service's works and improving the efficiency of problem solving. Secondly, 12396 WeChat public platform upgraded and developed an integrated "one-stop" micro-site to allow users know the agriculture market timely, releasing supply and demand information, etc. Thirdly, the 12396 WeChat public platform combined initiative push information with the user's automatic acquisition of information by sending keywords which increased user selectivity. The upgraded platform has obtained a good preliminary application achievement and recognized and welcomed by users. Finally, we concluded and looked forward to the future development direction of agricultural mobile consulting.
\end{abstract}

\section{Introduction}

Under the background of the rapid development of modern information technology, new models of information services are emerging and strengthening agricultural information services will be one of the effective measures to solve the "three rural issues" [1]. According to "The 41st China statistical report on internet development" [2] released by the China Internet Network Information Center, by December 2017, the number of Internet users in China reached 772 million, among them 735 million people used the mobile phone to access the internet, accounting for $97.5 \%$. With the continuous development of smart phones and the improvement of mobile phones application experience, the trend of mobile phones as the main Internet terminals for users has become more apparent. WeChat, an intelligent communication APP based on smart phones, is favored by users as it peerto-peer information reception and transmission methods. According to the 2017 WeChat application report, there are 902 million people visit WeChat every day on average, with an increase rate of $17 \%$ year-on-year, meanwhile, the number of voice messages and video calls via WeChat increased significantly. With the development of mobile Internet, WeChat APP will become a cost-effective approach offering agriculture information for more and more farmers who use it.

\subsection{The application status of WeChat public platform}

The WeChat public platform is a new service platform based on WeChat applications that provides business services and user management for individuals, businesses and organizations. With its huge user base and rich API interface, the WeChat public platform is favored by many developers. Until now, the number of WeChat public platform has exceeded 20 million since it launched in August 2012, among which the agriculture related accounts were 5688, increased 10 times compared with that during 2012 to 2016 [3]. Under such a development trend, exploring an integrated agricultural service platform

*Correspondence author: guoq@agri.ac.cn 
based on the WeChat public platform can increase the efficiency of agricultural science and technology information dissemination and improve the service accuracy to farmers.

\subsection{The necessity of upgrading 12396 WeChat public platform}

"12396 Beijing new rural sci-tech service hotline (abbreviation: 12396 hotline) " was established by the Rural Development Center of Beijing Municipal Science and Technology Commission and Beijing Academy of Agriculture and Forestry Sciences. It is a science and technology information service integrated platform for agriculture and provides agricultural technology information consulting services free with more than one hundred experts. The 12396 hotline WeChat public platform was opened in 2014 and accumulated a certain amount of users and reputation in the early stage. However, the services based on Tencent's backend system can only meet the basic needs of users. The following questions need to be addressed: Firstly, the backend of the WeChat public platform is mainly based on the PC side. If the expert wants to answer the question directly, he will go through all the consulting questions or through the secondary processing by the service personnel. As a result, the response efficiency is relatively low. What's more, the Tencent stipulates the replying time within 48 hours, reducing the flexibility of user consultation. Secondly, the number of front menu in the WeChat public platform is limited, so it is impossible to fully display all the service function. Thirdly, WeChat service messages can only be pushed 4 times per month with up to 8 messages each time, which relatively limits the interaction between WeChat public platform and users. In order to solve the above problems, 12396 hotline WeChat public platform was upgraded, combined with previous survey results and the experience in building process, operation and maintenance of the excellent agricultural WeChat public platform. After the platform upgraded, it will further improve service efficiency, optimize user experience, reduce service costs, accelerate publicity and promotion, and enhance brand image.

\section{Upgrading development of WeChat public platform}

\subsection{Integration of user consultation and expert solutions to WeChat public platform}

In order to improve the efficiency of the platform and reduce the difficulty of sorting out the agricultural technical problems, two external links, "user ask" and "expert answer", have been developed based on the 12396 hotline WeChat public platform, so that the users' questions can directly reach the expert without server's help. User can upload questions via "voice or text message" according to the agricultural field through "user ask" menu. The question was pushed to the expert who specialized in the corresponding fields. The expert can view the users' questions through the "expert answer" menu and can reply to the user's questions through mobile phone directly. Interfaces of the two menus are shown in Fig.1. Through these two external menus, users and experts can be connected directly, reducing unnecessary work in the middle and improving the efficiency of answering questions. In this way, it also avoids the problem that the WeChat public platform cannot directly interact with users after 48 hours.

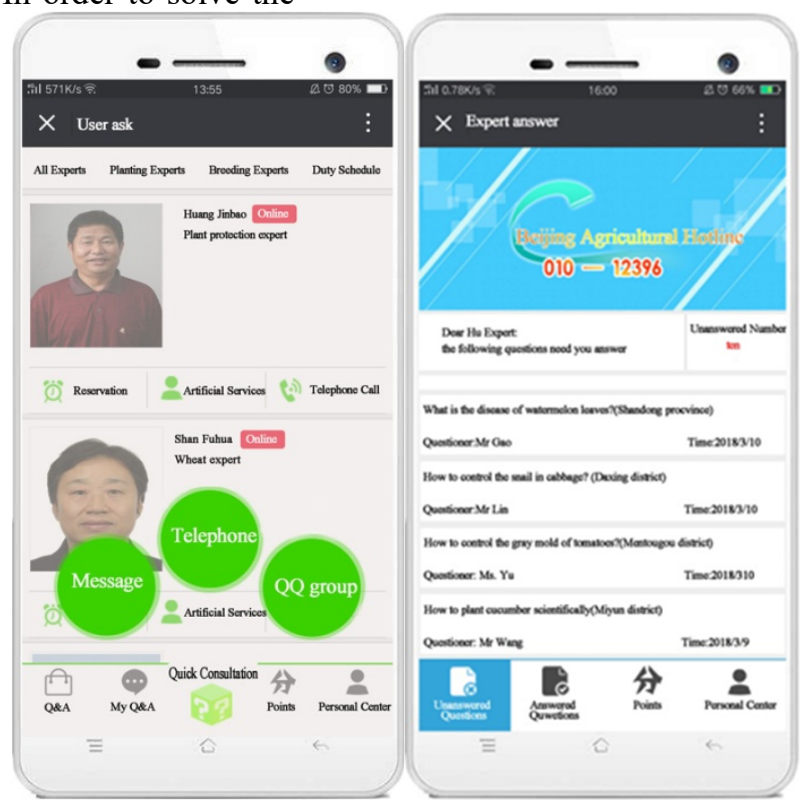

Fig. 1. Interfaces of the "user ask" (left) and "expert answer" (right)

\subsection{Development of micro-websites for comprehensive service on agricultural science and technology information}

The WeChat public platform provides a framework for the user personalized interface settings. Each public platform can only set three first-level menus and each first-level menu can only have five sub-menus. To some extent, it 
limits the public platform function relatively, if not add external links. In order to facilitate users to understand the development of the agricultural industry quickly, 12396 WeChat public platform develops an integrated service platform, the micro site. Interface of 12396 WeChat micro website is shown in Fig.2, There are mainly six functions of micro websites, i.e., "expert introduction" "online consultation" "information to get rich" "Varieties information" "supply-demand center" "market information". Through the micro website, users can learn about the information on latest crop variety and agricultural products market development, release supply and demand information and browse all the users' questions, so as to fully understand the dynamics of the agricultural industry.

\subsection{Combine user self-acquisition messages with platform-proactive push messages}

The Tencent also stipulates the number of messages to be sent in WeChat service account with four times a month, eight messages each time. To a certain extent, this kind of regulation regulates the WeChat public platform and prevents information flooding. However, it also relatively limits the interaction between the WeChat public platform and users. Combined with the characteristics of BeijingTianjin-Hebei agricultural development, 12396 WeChat public platform developed the "vegetable artifact" for better user serving. By sending keyword or resource number, people can obtain relevant information about the varieties and technologies according to the platform prompt messages. This self-service information acquisition method has effectively enhanced the interaction between the WeChat public platform and users and optimized the user's consultation experience.

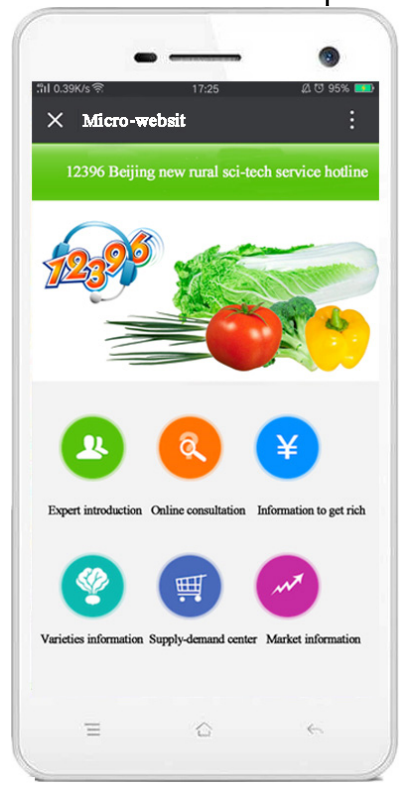

Fig. 2. Interface of $12396 \mathrm{WeChat} \mathrm{micro-website}$

\section{Promotion and application status}

Compared with the APP, the WeChat public platform only needs to scan the QR code with WeChat instead of installing, therefore, the promotion cost is relatively low [4].In order to obtain target users accurately, the 12396 WeChat public platform mainly uses a combination method of "online + offline" to enhance its influence and serve more people continuously. Online promotion: mainly through the 12396 Beijing new rural sci-tech service consultation channels, including WeChat, websites, Weibo, QQ group and other channels, to introduce functions of the upgraded WeChat public platform and available services, etc. Offline promotion: the online users were increased through offline promotion ways such as the 12396 countryside training, 12396 community service and special presentations, science and technology weeks.

After the 12396 WeChat public platform was upgraded, the initial promotion effect is good. At present, there are more than 6,000 registered users, including individual farmers, associations or cooperative members, agricultural technicians, ordinary citizens, enterprises, institutions, and researchers. Among all registered users, Beijing has the most, accounting for $43 \%$, BeijingTianjin-Hebei account for $50 \%$, followed by Shandong province. User distribution area is shown in Figure 3. The upgraded function of "micro-sites and vegetable artifact" have also been favored and praised by users, with clicks and visits continuously increased. Consultation questions include agricultural technology, policy, information about achieving prosperity, and market information. Categories of users' consulting questions are shown in Figure 4. 


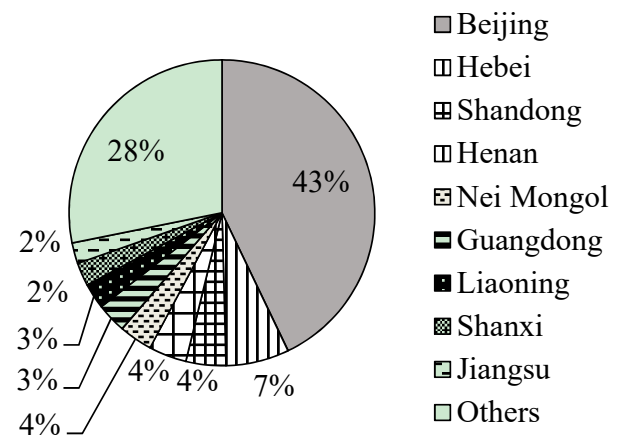

Fig. 3. User distribution area

\section{Conclusion and outlook}

The 12396 hotline WeChat public platform has upgraded as an integrated agricultural service platform by optimizing resource allocation, adding external links, to provide users with a better experience. In conclusion, we developed an agricultural information service mode based on WeChat public platform, constructed a kind of agricultural information service model for mobile applications, and provided an effective way for farmers to solve practical problems in agricultural production and management whenever and wherever.

With the continuous development of the WeChat public platform, new changes will also take place in WeChat-based agricultural science and technology information consulting services. First and foremost, agricultural science and technology consulting services will become increasingly intelligent [5].With the rapid development of science and technology, the trend of intelligent and automated mobile consulting services is becoming more and more obvious. Technologies such as intelligent voice and image recognition will be applied to agricultural science and technology consulting services. And we believe that the era of "AI+ agricultural technology consulting" will certainly be realized in the near future. Secondly, agricultural science and technology information consulting services will become more comprehensive [6]. The agricultural consulting service will be upgraded and developed into various aspects such as "buying, selling, asking, managing, and learning". It will not only provide agricultural technology information, but also show and sell new products and new technologies, to promote agricultural scientific research achievements to practical applications. Last but not least, the agricultural consulting service will integrate the advantages of new media, such as live broadcast, which characterized by good performance, rich content, strong interaction, and unlimited geographical areas. It can display the products, online survey, dialogue interview, and online training simultaneously, providing more convenient and efficient scientific and technological information services [7].

\section{Acknowledgment}

The research work was supported by the Beijing excellent

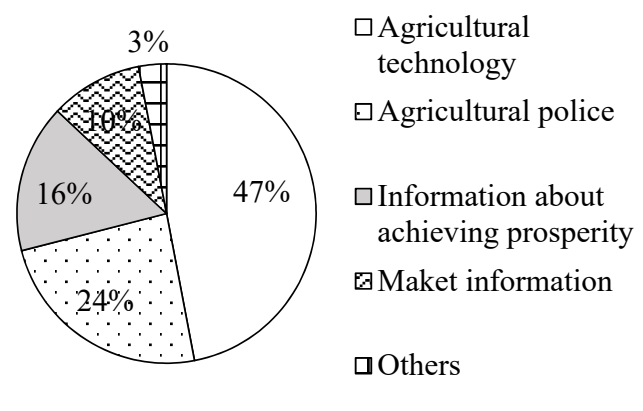

Fig. 4. Categories of users' consulting questions

talent project: Research on key technology of manmachine conversation in agricultural science and technology consultation and application of Beijing, Tianjin and Hebei, the international cooperation fund of BAAFS: A comparative study on the agricultural science and technology information service system in China, the United States and Canada, the 2018 Beijing financing agricultural funds: Application and demonstration of "Nongkexiaozhi" consulting service robot and WebAPP in agricultural production, the young scientist fund of BAAFS: Analysis of omnipotent agricultural technicians' training effect and relevant affecting factors in Beijing (NO.QNJJ201803)

\section{References}

1. Zheng, H. G., \& Hai-Yan, H. U. (2005). On agricultural information service models and their role in "agriculture, rural area, and farmer". Journal of Library \& Information Sciences in Agriculture. 17, 2, $137-140$ (2005).

2. CNNIC, The 41 st China statistical report on internet development,

(2017), http://cnnic.cn/gywm/xwzx/rdxw/201801/t20180131 70188.htm.

3. Deng, C. M., Liu, Y. Q., \& Yu-Ping, L. I.. Agricultural information service research based on wechat_a case of wechat public platform of tropical agricultural science and technology service. Journal of Anhui Agricultural Sciences. 44, 28, 237240, (2016).

4. Tan Baibing. We Chat service analysis and Application inagricultural extension information dissemination [D]. Chongqing Normal University, (2016).

5. Shewei, X. U., Wang, D., Denghua, L. I., \& Gao, L. Progress and outlook of china's "internet+" modern agriculture. Agriculture Network Information. 1. (2017)

6. Zhang, H. F. (2014). Prospect of application of agricultural information service platform based on android intelligent mobile phone. Heilongjiang Agricultural Sciences. 8, 126-128, (2014). 
7. Bai, Y.. Application of traditional media to new media integration on agricultural information service. Agriculture Network Information, 11, 55-57 (2014). 